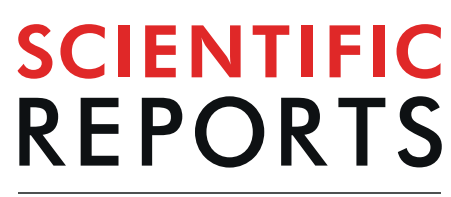

natureresearch

\title{
Genetic Analysis of Agronomic Traits and Grain Iron and Zinc Concentrations in a Doubled Haploid Population of Rice (Oryza sativa L.)
}

\author{
Mark lan C. Calayugan ${ }^{1,2}$, Andrea Kariza Formantes ${ }^{1,2}$, Amery Amparado ${ }^{1}$, \\ Gwen Iris Descalsota-Empleo ${ }^{1,2,3}$, Chau Thanh Nha ${ }^{1,4}$, Mary Ann Inabangan-Asilo ${ }^{1}$, \\ Zin Mar Swe ${ }^{1,5}$, Jose E. Hernandez ${ }^{2}$, Teresita H. Borromeo ${ }^{2}$, Antonio G. Lalusin' ${ }^{2}$, \\ Merlyn S. Mendioro ${ }^{2}$, Ma. Genaleen O. Diaz ${ }^{2}$, Celia B. dela Viña ${ }^{2}$, Russell Reinke ${ }^{1}$ \& \\ B. P. Mallikarjuna Swamy ${ }^{1 *}$
}

The development of micronutrient dense rice varieties with good agronomic traits is one of the sustainable and cost-effective approaches for reducing malnutrition. Identification of QTLs for high grain Fe and $\mathrm{Zn}$, yield and yield components helps in precise and faster development of high Fe and Zn rice. We carried out a three-season evaluation using IR05F102 x IR69428 derived doubledhaploid population at IRRI. Inclusive composite interval mapping was carried out using SNP markers and Best Linear Unbiased Estimates of the phenotypic traits. A total of 23 QTLs were identified for eight agronomic traits and grain Fe and Zn concentration that explained 7.2 to 22.0\% PV. A QTL by environment interaction analysis confirmed the stability of nine QTLs, including two QTLs for Zn on chromosomes 5 and 12 . One epistatic interaction for plant height was significant with 28.4\% PVE. Moreover, five QTLs were identified for Fe and Zn that harbor several candidate genes, e.g. OsZIP6 on QTL $q Z n_{5.1}$. A number of QTLs were associated with a combination of greater yield and increased grain $\mathrm{Zn}$ levels. These results are useful for development of new rice varieties with good agronomic traits and high grain Zn using MAS, and identification of genetic resources with the novel QTLs for grain Zn.

Rice constitutes a significant portion of the daily diet particularly in developing countries of Asia, supplying $50-80 \%$ of the daily caloric intake, proteins, minerals and vitamins etc ${ }^{1,2}$. The annual global rice production of 700 million tons was produced on an area of 158 million hectares in $2017^{2}$. However, rice production must be increased by additional 8-10 million tons each year and there is a strong impetus to improve the nutritional value with multiple essential vitamins and minerals to meet food and nutritional demands of a growing population ${ }^{2}$. Thus, there is an urgent need to breed for rice varieties with improved yield and nutritional value for sustaining global food and nutritional security ${ }^{3,4}$.

Micronutrients such as Fe and $\mathrm{Zn}$ are highly essential for the normal growth and development of both plants and animals ${ }^{5}$. The recommended human intake of $\mathrm{Fe}$ and $\mathrm{Zn}$ is $15 \mathrm{mg}$ per day ${ }^{6}$. However, it is rarely met by rice-based diets consumed in Asian populations ${ }^{7}$. Fe and $\mathrm{Zn}$ deficiencies significantly impact human health causing anemia, stunting, decreased immunity, poor cognitive development ${ }^{8}$. These have been recognized as global health concerns and need to be addressed on a priority basis ${ }^{9}$. Dietary diversification, food fortification, supplementation and biofortification have been advocated and are being employed to address malnutrition. Among

\footnotetext{
${ }^{1}$ International Rice Research Institute (IRRI), DAPO Box 7777, Metro Manila, Philippines. ${ }^{2}$ University of the Philippines Los Baños, Laguna, 4031, Philippines. ${ }^{3}$ University of the Southern Mindanao, Kabacan, Cotabato, 9407, Philippines. ${ }^{4}$ Cuu Long Delta Rice Research Institute (CLRRI), Cần Thơ, Vietnam. ${ }^{5}$ Department of Agriculture, Yezin, Myanmar.*email: m.swamy@irri.org
} 
these, biofortification of staple crops is in the forefront because of its affordability and easy access to the needy and targeted vulnerable populations, and the scale and impact that can be achieved by this intervention will be huge ${ }^{10}$.

Modern high-yielding rice varieties are poor source of nutrients in their polished form ${ }^{11}$. However, the huge genetic variability in grain mineral nutrients available in the rice germplasm can be exploited to develop biofortified high yielding rice varieties ${ }^{12}$. Even though genetic complexity and $\mathrm{G} x \mathrm{E}$ were reported to be a hindrance for improving mineral content with high yield, much progress has been achieved in elucidating the genetic basis and $\mathrm{G} \times \mathrm{E}$ effect on grain micronutrient accumulation, yield and yield related traits in rice ${ }^{13,14}$.

Identification of new donors for agronomic, yield and mineral nutrient traits, dissecting their genetic basis and using them to diversify the breeding population is a continuous process in developing high-yielding and nutritious rice varieties ${ }^{15-17}$. Several QTLs and genes have been identified and successfully used in rice improvement. Marker-Assisted Breeding (MAB) and Genomic Selection (GS) are powerful approaches to improve multiple complex traits ${ }^{18,19}$. The mainstreaming of mineral nutrients (i.e. including nutritive value as a standard selection criterion within breeding programs), especially grain $\mathrm{Zn}$ in staple crops has been well recognized and the application of genomics can enhance the rate of genetic gain ${ }^{10,20}$.

Doubled haploid lines (DH) are important genetic resources for mapping QTLs because of their rapid development with less deleterious alleles, minimal background noise and these fixed lines can be readily evaluated across years and locations ${ }^{21}$. DH populations together with Single Nucleotide Polymorphisms (SNPs) are an ideal combination for QTL mapping. They are cost-effective to assay using automated platforms, while allele calling, data analysis, and the database is straightforward due to their bi-allelic nature ${ }^{22}$. In previous studies several DH populations were genetically characterized for yield, yield components and grain mineral elements ${ }^{23,24}$. These DH populations utilized japonica type rice cultivars as donors in which grain $\mathrm{Zn}$ ranged from 10.37 to $18.00 \mathrm{ppm}$ in brown rice form ${ }^{18,24,25}$. On the other hand, other studies used Backcross Introgression Lines (BILs) derived from O. sativa 'Nipponbare' and O. meridionalis $\mathrm{W} 1627^{26}$, O. sativa cv. Swarna x O. nivara ${ }^{27}$, and Oryza sativa $\mathrm{x} O$. rufipogon ${ }^{28}$

Genomics based breeding approaches including MAS are becoming more common and to be efficient, research breeding programs need robust and stable QTLs across environments and genetic backgrounds ${ }^{29}$. Genotype by environment interactions (GEI) are the expression of QTLs and GEI QTLs are important as they significantly influence the total phenotypic variance and additive effect of the main effect QTL ${ }^{30}$. Moreover, haplotype-based allele mining was used to detect allelic variation in genes controlling agronomic traits ${ }^{31}$. On the other hand, gene pyramiding is important in improving the efficiency of biofortification breeding with SNP chip technology, allowing the development of lines with simultaneously introgressed small-effect QTLs for the precise development of genetic stocks ${ }^{32}$.

We characterized a DH population for yield, yield related traits and grain mineral elements, identified QTLs and candidate genes for yield and yield components, grain Fe and Zn; analyzed epistatic interactions, QTL x environment interactions, QTL pyramiding effects and haplotype analyses of major QTLs for YLD and Zn.

\section{Results}

Phenotypic analysis in DH population. The DH population showed wide variability for all traits measured in all three seasons (Supplementary Fig. 1). For agronomic traits, DF ranged from 71.7 to 106.2 days with a mean of 86.9 days. PH ranged from 70.1 to $127.7 \mathrm{~cm}$ with a mean of $95.5 \mathrm{~cm}$ while YLD ranged from 2669.9 to $7409.1 \mathrm{~kg} \mathrm{ha}^{-1}$ with a mean of $5446.1 \mathrm{~kg} \mathrm{ha}^{-1}$. GL ranged from 6.4 to $10.3 \mathrm{~mm}$ with a mean of $9.02 \mathrm{~mm}$ and GW ranged from 1.8 to $2.3 \mathrm{~mm}$ with a mean of $1.97 \mathrm{~mm}$. In grain $\mathrm{Fe}$ and $\mathrm{Zn}$ concentrations, Fe ranged from 2.8 to 5.8 ppm with mean of $4.1 \mathrm{ppm}$ while $\mathrm{Zn}$ ranged from 8.7 to $19.7 \mathrm{ppm}$ with a mean of $12.6 \mathrm{ppm}$ (Table 1). The parent IR05F102 exhibited higher values for agronomic traits NT, NP, and YLD in all three seasons while IR69428 exhibited higher values for DF, PH, TGW, GW, Fe and $\mathrm{Zn}$ across three seasons and BLUEs. Coefficient of variation for agronomic traits ranged from $2.88 \%$ to $19.20 \%$. Low CVs $(<10 \%)$ were recorded for DF, PH, TGW, GL, and GW. Genotypic effects were highly significant and heritability values were high (0.52-0.98) for all agronomic traits and grain Zn concentration while lower heritabilities were observed for Fe, viz. 0.22 in S3 and 0.49 in S1 (Table 1). Pearson's correlation co-efficient between BLUEs and the three season's data showed significant positive correlations ranging between 0.52 and 0.97 . Of the 45 possible correlations; 27 were significant in S1, with 12 positively correlated and 15 negatively correlated; while 26 were significant in S2, with 11 positively correlated and 15 negatively correlated; and 20 were significant in S3, of which 11 were positively correlated and nine were negatively correlated. A total of 29 correlations were significant using BLUEs, 13 of them were positive and 16 were negative (Fig. 1, Supplementary Table 1). Consistent strong positive correlations $(\mathrm{p}<0.001)$ were observed between NT \& NP, PH \& YLD, PH \& GL, YLD \& GL, TGW \& GW, Zn \& GW, and Zn \& Fe. Meanwhile, strong negative correlations were observed between DF \& TGW, GW \& NT, GW \& NP, GW \& YLD. The first two principal components (PC) accounted for $55.94 \%$ of the total variation (Fig. 2). PC1 contributed $30.34 \%$ of the total variation while PC2 contributed $25.60 \%$. For PC1, GL and YLD showed the highest positive loadings ( 0.46 and 0.44 ) among the agronomic traits analyzed, and Fe and $\mathrm{Zn}$ exhibited negative loadings ( -0.43 and -0.46$)$. This indicates that GL, YLD, $\mathrm{Fe}$ and $\mathrm{Zn}$ contributed most of the variation in PC1 (Supplementary Table 2). In PC2, TGW and GW contributed most of the variation with loadings of 0.37 and 0.40 , respectively.

Identification of QTLs. A total of 23 QTLs for agronomic traits and grain Fe and Zn concentrations were identified in the DH population based on BLUEs (Table 2, Fig. 3). They were distributed on chromosomes 1, 2, 3, $5,6,7,9,10$, and 12 . The phenotypic variance explained (PVE) by the QTLs ranged from $7.18 \%$ to $22.03 \%$. Two QTLs for DF ( $q D F_{1.1}$ and $q D F_{3.1}$ ) were identified on chromosomes 1 and 3. These QTLs explained $14.82 \%$ and $12.63 \%$ PV. QTL $q D F_{3.1}$ was contributed by the high-yielding parent IR05F102. One QTL each was identified on chromosome 3 for PH, NT and NP, each explained more than $12 \%$ PV. Four QTLs for YLD $\left(q Y L D_{1.1}, q Y L D_{3.1}\right.$, $q Y L D_{7.1}$ and $\left.q D F_{12.1}\right)$ were identified on chromosomes $1,3,7$, and 12 contributed by IR05F102. Three of them 


\begin{tabular}{|c|c|c|c|c|c|c|c|c|}
\hline \multirow[b]{2}{*}{ Trait } & \multirow[b]{2}{*}{ Season } & \multicolumn{2}{|l|}{ Parents } & \multicolumn{2}{|l|}{ DH lines } & \multicolumn{3}{|l|}{ ANOVA } \\
\hline & & IR05F102 & IR 69428 & Range & Mean \pm SE & CV (\%) & $\begin{array}{l}\text { Genotypic } \\
\text { effects }\end{array}$ & $\mathbf{H}^{2}$ \\
\hline \multirow{4}{*}{ DF (days) } & S1 & 87 & 96.5 & $75.0-107.5$ & $83.74 \pm 0.53$ & 7.63 & $13.4^{*}$ & 0.93 \\
\hline & S2 & 89 & 100 & $75.0-109.0$ & $87.18 \pm 0.50$ & 6.99 & $16.4^{* *}$ & 0.94 \\
\hline & S3 & 91 & 94.5 & $72.0-108.0$ & $90.18 \pm 0.45$ & 6.1 & $46.9 * *$ & 0.98 \\
\hline & BLUEs & 88.5 & 94.5 & $71.7-106.2$ & $86.98 \pm 0.45$ & 6.25 & - & - \\
\hline \multirow{4}{*}{$\mathrm{PH}(\mathrm{cm})$} & S1 & 88.2 & 93.4 & $71.2-130.1$ & $93.98 \pm 0.74$ & 9.6 & $6.8^{* * *}$ & 0.85 \\
\hline & S2 & 96.1 & 100.8 & $65.5-122.0$ & $92.69 \pm 0.77$ & 10.08 & $6.4^{* * *}$ & 0.85 \\
\hline & S3 & 102.3 & 101.5 & $67.2-129.8$ & $99.50 \pm 0.91$ & 10.98 & $4.5^{* * *}$ & 0.78 \\
\hline & BLUEs & 95.4 & 98.9 & $70.1-127.7$ & $95.48 \pm 0.72$ & 9.11 & - & - \\
\hline \multirow{4}{*}{ NT } & S1 & 14.5 & 10 & 9.3-22.89 & $15.42 \pm 0.18$ & 14.02 & $2.1^{* * *}$ & 0.52 \\
\hline & S2 & 11.8 & 7.8 & $9.5-18.5$ & $13.29 \pm 0.15$ & 13.99 & $2.8^{* * *}$ & 0.63 \\
\hline & S3 & 11.6 & 7.3 & $7.7-17.0$ & $12.13 \pm 0.16$ & 16.33 & $2.2^{* * *}$ & 0.55 \\
\hline & BLUEs & 12.7 & 8.4 & \begin{tabular}{|l|}
$10.1-18.7$ \\
\end{tabular} & $13.87 \pm 0.13$ & 11.22 & - & - \\
\hline \multirow{4}{*}{ NP\} $&{\text { S1 }} &{\begin{array}{|l|}13.1 \\
\end{array}} &{9} &{\text { 9.0-20.89 }} &{14.18 \pm 0.17} &{14.57} &{2.2^{* * *}} &{0.53} \\
{\hline} &{\text { S2 }} &{11.6} &{7.8} &{9.3-18.5} &{13.08 \pm 0.15} &{13.89} &{2.7 * *} &{0.61} \\
{\hline} &{\text { S3 }} &{11.6} &{7.1} &{7.5-16.83} &{11.95 \pm 0.17} &{17.03} &{2.3^{* * *}} &{0.57} \\
{\hline} &{\text { BLUEs }} &{12.2} &{8} &{9.5-17.9} &{13.32 \pm 0.13} &{11.5} &{-} &{-} \\
{\hline \multirow{4}{*}{\operatorname{YLD}\left(\mathrm{kg} \mathrm{ha}^{-1}\right)}\operatorname { Y L D } ( \mathrm { kg } \mathrm { ha } ^ { - 1 } )} &{\text { S1 }} &{8340.6} &{2186.5} &{\text { 3011.6-13163.6 }} &{6856.35 \pm 159.02} &{28.22} &{3.0^{* * *}} &{0.66} \\
{\hline} &{\text { S2 }} &{8018.6} &{4797.2} &{3022.4-9767.3} &{6474.54 \pm 121.15} &{22.76} &{5.8^{* * *}} &{0.83} \\
{\hline} &{\text { S3 }} &{3605.3} &{765.2} &{450.1-5779.3} &{3095.04 \pm 85.37} &{33.44} &{4.5^{* * *}} &{0.78} \\
{\hline} &{\text { BLUEs }} &{6425.1} &{3154.4} &{\begin{array}{|l|}2669.9-7409.1 \\
\end{array}} &{5446.10 \pm 85.93} &{19.2} &{-} &{-} \\
{\hline \multirow{4}{*}{\text { TGW (g) }}\text { TGW (g) }} &{\text { S1 }} &{21} &{30.1} &{16.1-31.3} &{25.25 \pm 0.21} &{10.25} &{2.7 * *} &{0.62} \\
{\hline} &{\text { S2 }} &{27.7} &{29} &{\begin{array}{|l|}16.0-29.7 \\
\end{array}} &{23.61 \pm 0.19} &{9.95} &{12.0 * *} &{0.91} \\
{\hline} &{\text { S3 }} &{26.4} &{26.8} &{15.6-28.2} &{23.23 \pm 0.20} &{10.44} &{9.2^{* * *}} &{0.89} \\
{\hline} &{\text { BLUEs }} &{27.4} &{28.7} &{16.6-29.4} &{24.05 \pm 0.19} &{9.43} &{-} &{-} \\
{\hline \multirow{4}{*}{\text { GL (mm) }}\text { GL (mm) }} &{\text { S1 }} &{8.1} &{8.1} &{6.4-10.6} &{9.04 \pm 0.06} &{8.31} &{18.7 * *} &{0.94} \\
{\hline} &{\text { S2 }} &{9.6} &{8.2} &{6.2-10.3} &{8.94 \pm 0.06} &{8.46} &{14.9 * *} &{0.93} \\
{\hline} &{\text { S3 }} &{9.6} &{8.2} &{6.6-10.4} &{9.10 \pm 0.06} &{8.16} &{13.4^{* *}} &{0.92} \\
{\hline} &{\text { BLUEs }} &{9.1} &{8.2} &{6.4-10.3} &{9.02 \pm 0.06} &{8.05} &{-} &{-} \\
{\hline \multirow{4}{*}{\mathrm{GW}(\mathrm{mm})}\mathrm { GW } ( \mathrm { mm } )} &{\text { S1 }} &{1.8} &{2.3} &{1.8-2.3} &{1.94 \pm 0.006} &{3.79} &{9.3^{* * *}} &{0.87} \\
{\hline} &{\text { S2 }} &{2.1} &{2.4} &{1.96-2.3} &{2.05 \pm 0.005} &{2.7} &{4.4^{* * *}} &{0.7} \\
{\hline} &{\text { S3 }} &{2} &{2.4} &{1.7-2.4} &{1.92 \pm 0.006} &{4.06} &{4.1 * *} &{0.7} \\
{\hline} &{\text { BLUEs }} &{1.9} &{2.4} &{1.8-2.3} &{1.97 \pm 0.006} &{2.88} &{-} &{-} \\
{\hline \multirow{4}{*}{\mathrm{Fe}(\mathrm{ppm})}\mathrm { Fe } ( \mathrm { ppm } )} &{\text { S1 }} &{4} &{\begin{array}{|l|}3.9 \\
\end{array}} &{2.3-5.6} &{3.71 \pm 0.05} &{15.72} &{1.9^{* * *}} &{0.49} \\
{\hline} &{\text { S2 }} &{3.6} &{5.6} &{3.2-7.5} &{5.11 \pm 0.06} &{14.55} &{1.6^{* * *}} &{0.35} \\
{\hline} &{\text { S3 }} &{2.7} &{1.7} &{\text { 1.4-6.6 }} &{3.36 \pm 0.06} &{23.05} &{1.3^{*}} &{0.22} \\
{\hline} &{\text { BLUEs }} &{3.6} &{3.9} &{2.8-5.8} &{4.06 \pm 0.04} &{12.55} &{ } &{ } \\
{\hline \multirow{4}{*}{\mathrm{Zn}(\mathrm{ppm})}\mathrm { Zn } ( \mathrm { ppm } )} &{\text { S1 }} &{\begin{array}{|l|}14.4 \\
\end{array}} &{23.5} &{7.8-26.9} &{13.47 \pm 0.27} &{24.16} &{8.0 * *} &{0.87} \\
{\hline} &{\text { S2 }} &{12.4} &{13.7} &{\text { 9.5-20.6 }} &{13.85 \pm 0.17} &{14.68} &{3.5^{* * *}} &{0.71} \\
{\hline} &{\text { S3 }} &{9.4} &{9.2} &{6.8-21.6} &{10.63 \pm 0.18} &{20.45} &{3.9 * *} &{0.75} \\
{\hline} &{\text { BLUEs }} &{11.9} &{14.8} &{8.7-19.7} &{12.64 \pm 0.17} &{16.59} &{-} &{-} \\
$\hline}
\end{tabular}

Table 1. Phenotypic variation for agronomic traits, Fe and $\mathrm{Zn}$ concentration in $\mathrm{DH}$ population. ${ }^{\dagger} \mathrm{DF}$ : days to flowering (days); PH: plant height (cm); NT: number of tillers; NP: number of panicles; YLD: yield (kg ha - 1); TGW: thousand grain weight (g); GL: grain length (mm); GW: grain width (mm); Fe: Iron (ppm); and Zn: Zinc (ppm).

had PVE values of more than $10 \% . q Y L D_{3.1}$ had the highest PVE (22.03\%). One QTL for TGW was identified on chromosome $6\left(q T G W_{6.1}\right)$ contributed by IR05F102 with a PVE of $15.79 \%$. Similarly, four QTLs were identified for GL, one each on chromosomes 1, 6, 7 and 10. The PVE of these QTLs varied from 7.35\% to $16.45 \% . q G L_{1.1}$, $q G L_{6.1}$, and $q G L_{7.1}$ had a PVE of more than $10 \%$ each. $q G L_{6.1}$ had the highest PVE (16.45\%). While, three QTLs for GW ( $q G W_{2.1}, q G W_{5.1}$, and $\left.q G W_{9.1}\right)$ were identified on chromosomes 2, 5, and 9 all derived from IR69428 with PVE values of $11.71 \%, 10.31 \%$, and $14.76 \%$, respectively. Two QTLs for $\mathrm{Fe}\left(q F e_{9.1}\right.$ and $\left.q \mathrm{Fe}_{12.1}\right)$ were identified on chromosomes 9 and 12 derived from IR69428 with PVE values of $11.79 \%$ and $13.34 \%$, respectively. But for Zn, four QTLs were identified on chromosomes 1, 5, 9, and 12 contributed by IR69428. Three $\left(q Z n_{5.1}, q Z n_{9.1}, q Z n_{12.1}\right)$ of them had PVE values of more than 10\%. $q Z n_{12.1}$ had the highest PVE (15.26\%).

QTL co-locations. Three QTL co-locations consisting of QTLs for two traits each were observed on chromosomes 3 and 9, two for agronomic traits and one for grain mineral elements (Fig. 3). Interestingly, these traits 


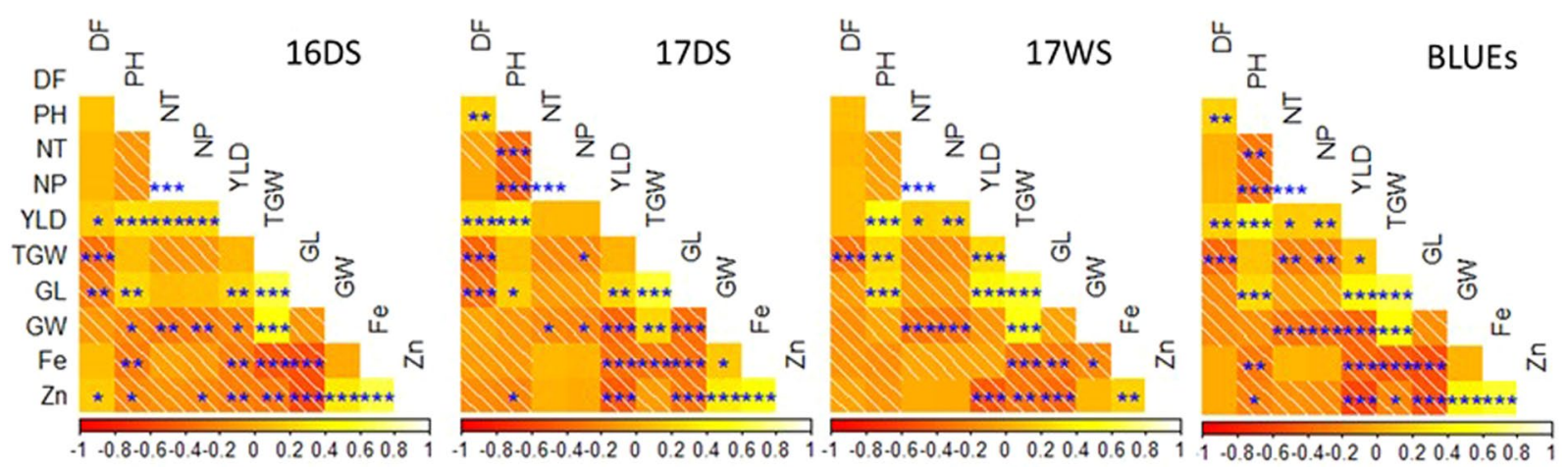

Figure 1. Correlations among agronomic traits and grain $\mathrm{Fe}$ and $\mathrm{Zn}$ concentrations in $\mathrm{DH}$ population. *Indicates significance at $p \leq 0.05$. **Indicates significance at $p \leq 0.01 . * * *$ Indicates significance at $p \leq 0.001$. $\dagger$ DF: days to flowering (days); PH: plant height (cm); NT: number of tillers; NP: number of panicles; YLD: yield $\left(\mathrm{kgha}^{-1}\right)$; TGW: thousand grain weight (g); GL: grain length $(\mathrm{mm})$; GW: grain width (mm); Fe: Iron (ppm); and Zn: Zinc (ppm).

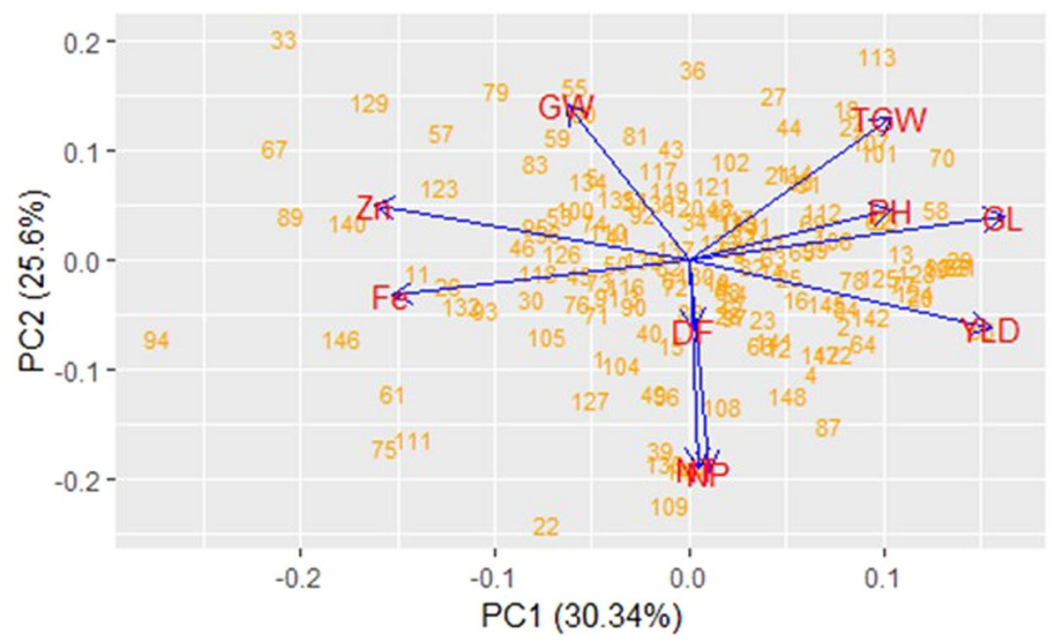

Figure 2. Principal component analysis in $\mathrm{DH}$ population using the two $\mathrm{PC}$ with highest proportion of variance. Numbers inside the box correspond to DH lines.

that share common QTLs were positively correlated. Agronomic trait QTLs: $q D F_{3.1}$ and $q P H_{3.1}$ were co-located on chromosome 3 at 33.97-33.98 Mb within SNP marker interval 3500757-3501392 with allelic contribution from P1. QTLs $q N T_{3.1}$ and $q N P_{3.1}$ were co-located on chromosome 3 at $34.72-35.23 \mathrm{Mb}$ within SNP marker interval id3017089 - 3536043 and with allelic contribution from P1. On the other hand, grain mineral element QTLs, $q \mathrm{Fe}_{9.1}$ and $q \mathrm{Zn}_{9.1}$ were co-located on chromosome 9 at 19.79-20.13 Mb within SNP marker interval id9809545$9819278 \mathrm{Mb}$ with allelic contribution from P2.

QTL x environment interaction analysis. To understand the stability and interaction of the identified QTLs with environment, QEI analysis was conducted. Estimated effects of 10 consistent QEI QTLs can be found in Table 3. One consistent QEI QTL was detected for DF on chromosome 1; two for YLD on chromosomes 3 and 7; two for GL on chromosomes 1 and 10; three for GW on chromosomes 3, 5 and 9; and two for Zn on chromosomes 9 and 12 (Fig. 4). All identified QEI QTLs were stable as indicated by the larger $\operatorname{LOD}_{\mathrm{A}}(1.55-9.67)$ than $\operatorname{LOD}_{\mathrm{AE}}(0.12-3.83)$ values and larger $\mathrm{PVE}_{\mathrm{A}}(1.93-13.91 \%)$ than $\operatorname{PVE}_{\mathrm{AE}}(0.05-3.21 \%)$ values (Table 3).

Epistatic interaction analysis. One epistatic interaction for $\mathrm{PH}$ was identified in the $\mathrm{DH}$ population (Supplementary Table 4; Fig. S2). The major di-genic epistatic interaction was identified between loci on chromosomes 3 with SNP marker interval id3495083 - $3500757 \mathrm{Mb}$ and on chromosome 7 with SNP marker interval id7862147 - $7892971 \mathrm{Mb}$ with a PVE value of $28.40 \%$.

Candidate genes underlying QTLs for agronomic traits, Fe and Zn. Seven agronomic trait QTLs and five Fe and Zn QTLs were harbored in or near candidate genes (Table 4). For agronomic traits, two candidate genes (OsLFL1 and OsHD6) were identified for DF located on chromosomes 1 and 3. OsLFL1 with locus id Os01g0713600 was identified as a gene for flower development while OsHD6 with locus id Os03g0762000 


\begin{tabular}{|c|c|c|c|c|c|c|c|c|}
\hline Trait $^{\dagger}$ & QTL & Chr & Marker Interval & POS (Mb) & LOD & PVE (\%) & Add & Allele \\
\hline \multirow{2}{*}{ DF (days) } & $q D F_{1.1}$ & 1 & 1059782-id1020910 & $32.14-33.67$ & 8.00 & 14.82 & -3.46 & P2 \\
\hline & $q D F_{3.1}$ & 3 & $3500757-3501392$ & $33.97-33.98$ & 6.70 & 12.63 & 2.63 & P1 \\
\hline $\mathrm{PH}(\mathrm{cm})$ & $q \mathrm{PH}_{3.1}$ & 3 & $3500757-3501392$ & $33.97-33.98$ & 3.82 & 12.00 & 3.25 & P1 \\
\hline NT & $q N T_{3.1}$ & 3 & id3017089-3536043 & $34.72-35.23$ & 5.46 & 15.76 & 0.76 & P1 \\
\hline $\mathrm{NP}$ & $q N P_{3.1}$ & 3 & id3017089-3536043 & $34.72-35.23$ & 5.66 & 16.35 & 0.76 & P1 \\
\hline \multirow{4}{*}{ YLD $\left(\mathrm{kg} \mathrm{ha}^{-1}\right)$} & $q Y L D_{1.1}$ & 1 & id1006289-279787 & $8.17-9.22$ & 5.39 & 11.91 & 501.63 & P1 \\
\hline & $q Y L D_{3.1}$ & 3 & 3495083-3500757 & $33.71-33.97$ & 9.36 & 22.03 & 499.34 & P1 \\
\hline & $q Y L D_{7.1}$ & 7 & 7956643-id7005792 & $28.64-28.83$ & 3.37 & 7.18 & 340.72 & P1 \\
\hline & $q Y L D_{12.1}$ & 12 & 12776589-id12006657 & $18.59-19.78$ & 4.95 & 10.95 & 400.64 & P1 \\
\hline TGW (g) & $q T G W_{6.1}$ & 6 & 6461495-6585321 & $17.27-20.14$ & 4.61 & 15.79 & 0.90 & P1 \\
\hline \multirow{4}{*}{$\mathrm{GL}(\mathrm{mm})$} & $q G L_{1.1}$ & 1 & id1019016-1058637 & $31.52-32.09$ & 6.05 & 14.41 & 0.31 & P1 \\
\hline & $q G L_{6.1}$ & 6 & c6p22953431-6702537 & $22.95-22.96$ & 6.59 & 16.45 & 0.25 & P1 \\
\hline & $q G L_{7.1}$ & 7 & 7089136-7102234 & $5.00-5.44$ & 5.55 & 12.94 & 0.22 & P1 \\
\hline & $q G L_{10.1}$ & 10 & id10000771-10022933 & $2.66-2.79$ & 3.27 & 7.35 & 0.23 & P1 \\
\hline \multirow{3}{*}{$\mathrm{GW}(\mathrm{mm})$} & $q G W_{2.1}$ & 2 & id2002293-1487575 & \begin{tabular}{|l|l|}
$4.36-4.75$ \\
\end{tabular} & 3.38 & 11.71 & -0.02 & P2 \\
\hline & $q G W_{5.1}$ & 5 & $4878555-4884069$ & $2.26-2.43$ & 3.06 & 10.31 & -0.02 & P2 \\
\hline & $q G W_{9,1}$ & 9 & 9712393-id9007001 & $16.53-19.66$ & 4.24 & 14.76 & -0.03 & P2 \\
\hline \multirow{2}{*}{$\mathrm{Fe}(\mathrm{ppm})$} & $q F e_{9.1}$ & 9 & 9809545-9819278 & $19.79-20.13$ & 3.36 & 11.79 & -0.25 & P2 \\
\hline & $q \mathrm{Fe}_{12.1}$ & 12 & $12702072-12732307$ & $16.98-17.57$ & 3.98 & 13.34 & -0.20 & P2 \\
\hline \multirow{4}{*}{$\mathrm{Zn}(\mathrm{ppm})$} & $q Z n_{1.1}$ & 1 & id1008679-439764 & $12.71-13.79$ & 3.14 & 8.96 & -0.79 & P2 \\
\hline & $q Z n_{5.1}$ & 5 & $4904312-4908650$ & $3.26-3.42$ & 4.13 & 12.15 & -0.84 & P2 \\
\hline & $q Z n_{9,1}$ & 9 & 9809545-9819278 & $19.79-20.13$ & 4.56 & 13.79 & -0.96 & P2 \\
\hline & $q Z n_{12.1}$ & 12 & c12p4887439-12172332 & $4.88-5.37$ & 5.20 & 15.26 & -0.77 & P2 \\
\hline
\end{tabular}

Table 2. QTLs for agronomic traits and grain element concentrations in $\mathrm{DH}$ population. ${ }^{\dagger} \mathrm{DF}$ : days to flowering (days); PH: plant height (cm); NT: number of tillers; NP: number of panicles; YLD: yield (kg ha-1); TGW: thousand grain weight (g); GL: grain length (mm); GW: grain width (mm); Fe: Iron (ppm); and Zn: Zinc (ppm).

was for days to heading. One candidate gene, OsLTS1 was identified for PH on chromosome 3 with locus id Os03g0837300. Four candidate genes were identified for YLD such as, OsDST, OsIPT4, OsMED5_3, and OsNAC139 on chromosomes 3, 7, and 12, respectively. Two candidate genes for GW, OsSRS3 and OsGS5 were identified on chromosome 5. Among QTLs for grain mineral element concentrations, for Fe, OsLysM-RLK10 and OsSWEET13 were candidate genes identified on chromosome 9 and 12, while candidate genes OsGATA8, OsSar1b, OsZIP6, and Os09g0511500 on chromosomes 1, 5, and 9 were identified for Zn (Supplementary Figs. S3 and S4). There were significant sequence differences in the candidate genic regions of the major QTLs (Supplementary Table S5).

QTL classes for YLD and Zn. To understand the effects of combining the identified QTLs for YLD and Zn in this study, QTL classes were calculated. The mean YLD of DH lines without QTLs was $4430.9 \mathrm{~kg} \mathrm{ha}^{-1}$. On the other hand, the mean Zn of the DH lines without QTLs was $11.18 \mathrm{ppm}$. The genotype classes for YLD and Zn showed a wide range of $4129.4-6373.0 \mathrm{~kg} \mathrm{ha}^{-1}$ and $11.1-17.7 \mathrm{ppm}$, respectively. An increase in YLD and Zn was observed with an increase in the number of QTLs (Tables 5 and S3). The IR05F102 allele at all four loci increased YLD. DH lines with three to four QTLs (genotype class 15 and 16) showed the highest YLD, 6373.0 kg ha $\mathrm{knd}^{-1}$ $6285.7 \mathrm{~kg} \mathrm{ha}^{-1}$, respectively, among all YLD genotype classes. The IR69428 alleles at all four loci increased $\mathrm{Zn}$. DH lines with four QTLs $\left(q Z n_{1.1}+q Z n_{5.1}+q Z n_{9.1}+q Z n_{12.1}\right)$ showed the highest $\mathrm{Zn}, 17.7 \mathrm{ppm}$, among all $\mathrm{Zn}$ genotype classes.

Identification of $\mathrm{DH}$ lines with good agronomic traits and high grain $\mathrm{Zn}$. The top ten high $\mathrm{Zn}$ lines were identified using BLUEs of the 148 DH lines (Table 6). IR 91153-AC 113-1 was early for DF and had the highest YLD $\left(6697.23 \mathrm{~kg} \mathrm{ha}^{-1}\right)$ among the top lines. All four YLD QTLs $\left(q Y L D_{1.1}, q Y L D_{3.1}, q Y L D_{7.1}, q Y L D_{12.1}\right)$ and one Zn QTL $\left(q Z n_{12.1}\right)$ were detected in this line. IR 91153-AC726-1 had the highest value for Zn and Fe of 16.21 and $4.82 \mathrm{ppm}$, respectively. Two Zn QTLs were identified in this line $\left(q Z n_{5.1}, q Z n_{12.1}\right)$ and one YLD QTL $\left(q Y L D_{1.1}\right)$. These DH lines can be used as donors in breeding programs or can be directly tested in multi-location trials to further evaluate their performance and potential to be released as high $\mathrm{Zn}$ rice varieties.

\section{Discussion}

Compared to other cereals, rice is a poor source of essential micronutrients to fulfill daily human nutritional requirements ${ }^{33}$. $\mathrm{Zn}$ biofortification is considered to be a major solution that appears to be the most sustainable and cost-effective approach for addressing micronutrient malnutrition or hidden hunger ${ }^{34}$. Knowledge of genetic variation in agronomic traits, grain mineral elements concentration such as Fe and $\mathrm{Zn}$ and genes underlying allelic variation is vital for rice biofortification breeding to fast track the development of rice varieties that can make a positive contribution to human health. In this study, a DH population of rice was used to map QTLs for 


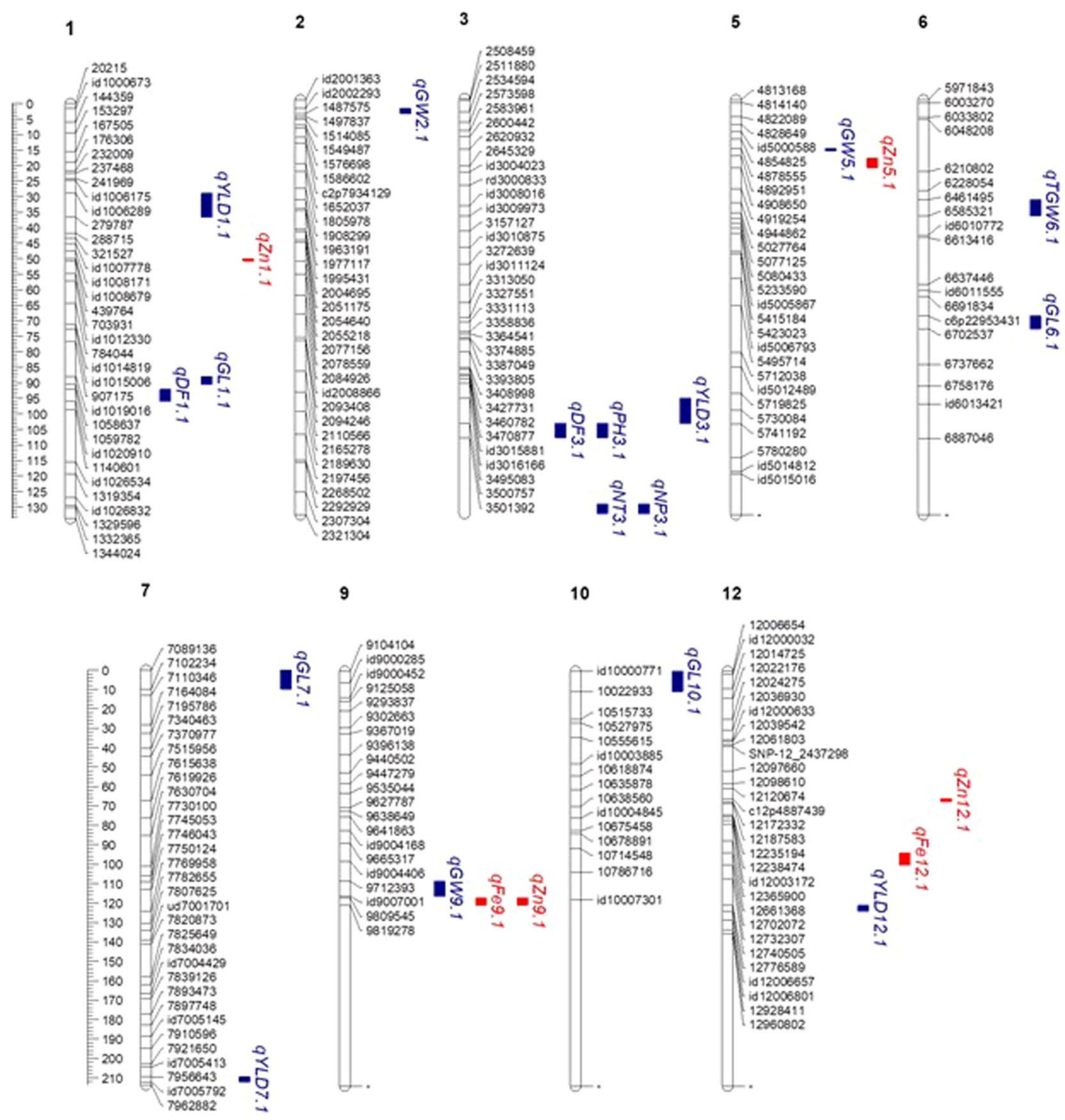

Figure 3. QTLs identified for agronomic traits and grain micronutrient concentrations in DH population. $\dagger$ Blue font: QTLs for agronomic traits; red font: QTLs for grain element concentrations.

agronomic traits, Fe and Zn concentrations with SNP markers and BLUEs. Epistatic interactions, QTL by environment interactions, QTL pyramiding effects and haplotype analysis of major QTLs for YLD and Zn were also examined.

The $\mathrm{DH}$ population showed wide variation in all traits studied which specifies the traits complex and polygenic nature. BLUEs for grain Fe showed relatively little variation while grain Zn ranged from 8.7 to $19.7 \mathrm{ppm}$. The variation observed in the $\mathrm{DH}$ population for agronomic traits and grain $\mathrm{Zn}$ is important and a prerequisite for QTL mapping ${ }^{35}$. The variation indicates that a proportion of the phenotypic variance can be attributed to genotypic variance and that the agronomic traits and grain $\mathrm{Zn}$ can be exploited through selective breeding ${ }^{36}$. A wide range of variation also displayed the role of genotype as well as the effects of environment on the expression of the studied traits ${ }^{37}$. Several prior studies have also reported significant genetic variation specifically for grain $\mathrm{Zn}$ concentration $^{38-40}$ which supports that selection for high levels of $\mathrm{Zn}$ coupled with advanced molecular marker technologies is a feasible approach.

High $\mathrm{H}^{2}$ values $(>0.50)$ for all agronomic traits and grain $\mathrm{Zn}$ concentration were observed in the $\mathrm{DH}$ population which is consistent with previous studies that also work with rice agronomic traits and grain micronutrient concentrations ${ }^{41-43}$. However, the heritability was much lower for grain Fe concentration. Reliability of early generation selection of highly heritable agronomic traits (DF, PH, TGW, GW, and GL) is highly feasible, which may result in significant response to selection ${ }^{44}$. The low heritability observed for Fe indicates significant influence of environment and early selection for $\mathrm{Fe}$ is not feasible.

The first two PCs explained 55.94\% of the total variation observed in the DH population. In general, principal components with vector coefficients more than 0.3 irrespective of their direction of influence are considered important $^{45}$. Component loadings for each principal component revealed agronomic traits, such as YLD, TGW, 


\begin{tabular}{|c|c|c|c|c|c|c|c|c|c|c|c|c|c|}
\hline \multirow[b]{2}{*}{ Trait } & \multirow[b]{2}{*}{ QTL } & \multirow[b]{2}{*}{ Chr } & \multirow[b]{2}{*}{ Marker Interval } & \multirow[b]{2}{*}{ LOD } & \multirow{2}{*}{\begin{tabular}{|l|} 
LOD \\
(A) \\
\end{tabular}} & \multirow{2}{*}{\begin{tabular}{|l|} 
LOD \\
$(\mathrm{AE})$
\end{tabular}} & \multirow[b]{2}{*}{ PVE(\%) } & \multirow{2}{*}{\begin{tabular}{|l} 
PVE (\%) \\
(A)
\end{tabular}} & \multirow{2}{*}{\begin{tabular}{|l|} 
PVE (\%) \\
(AE) \\
\end{tabular}} & \multicolumn{3}{|c|}{ Additive effect } & \multirow{2}{*}{\begin{tabular}{|l|} 
Average \\
effect \\
\end{tabular}} \\
\hline & & & & & & & & & & 2016DS & 2017DS & 2017WS & \\
\hline $\mathrm{DF}$ & $q D F_{l .1}$ & 1 & 1059782-id1020910 & 8.13 & 6.51 & 1.62 & 7.41 & 5.9 & 1.52 & 1.24 & -1.21 & -0.04 & -1.97 \\
\hline \multirow[t]{2}{*}{ YLD } & $q Y L D_{3.1}$ & 3 & 3495083-3500757 & 6.93 & 4.84 & 2.09 & 7.87 & 6.12 & 1.75 & -60.78 & 266.09 & -205.31 & 368.77 \\
\hline & $q Y L D_{7.1}$ & 7 & id7005792-7962882 & 5.38 & 1.55 & 3.83 & 2.93 & 1.93 & 1 & -240.07 & 41.51 & 198.55 & 252.56 \\
\hline \multirow[t]{2}{*}{ GL } & $q G L_{1.1}$ & 1 & $1058637-1059782$ & 7.69 & 6.55 & 1.13 & 6.54 & 5.35 & 1.18 & -0.07 & 0.14 & -0.07 & 0.22 \\
\hline & $q G L_{10.1}$ & 10 & id10000771-10022933 & 3.33 & 3.2 & 0.12 & 2.62 & 2.53 & 0.09 & 0.04 & -0.01 & -0.03 & 0.15 \\
\hline \multirow[t]{3}{*}{ GW } & $q G W_{2.1}$ & 2 & id2002293-1487575 & 7.07 & 4.86 & 2.21 & 10.21 & 7.78 & 2.43 & -0.01 & 0.02 & -0.01 & -0.03 \\
\hline & $q G W_{5.1}$ & 5 & $4878555-4884069$ & 4.26 & 2 & 2.25 & 5.4 & 3.09 & 2.31 & -0.02 & 0.01 & 0.01 & -0.02 \\
\hline & $q G W_{9.1}$ & 9 & 9712393-id9007001 & 3.58 & 3.3 & 0.28 & 5.04 & 4.98 & 0.05 & 0 & 0 & 0 & -0.02 \\
\hline \multirow[t]{2}{*}{$\mathrm{Zn}$} & $q Z n_{9,1}$ & 9 & 9809545-9819278 & 5.48 & 2.61 & 2.87 & 7.09 & 3.88 & 3.21 & 0.05 & -0.6 & 0.55 & -0.51 \\
\hline & $q Z n_{12.1}$ & 12 & c12p4887439-12172332 & 10.33 & 9.67 & 0.66 & 16.93 & 13.91 & 3.02 & -0.38 & -0.11 & 0.49 & -0.78 \\
\hline
\end{tabular}

Table 3. Estimated effects of QTL by Environment Interaction QTLs of agronomic traits and grain element concentrations identified in the DH population.
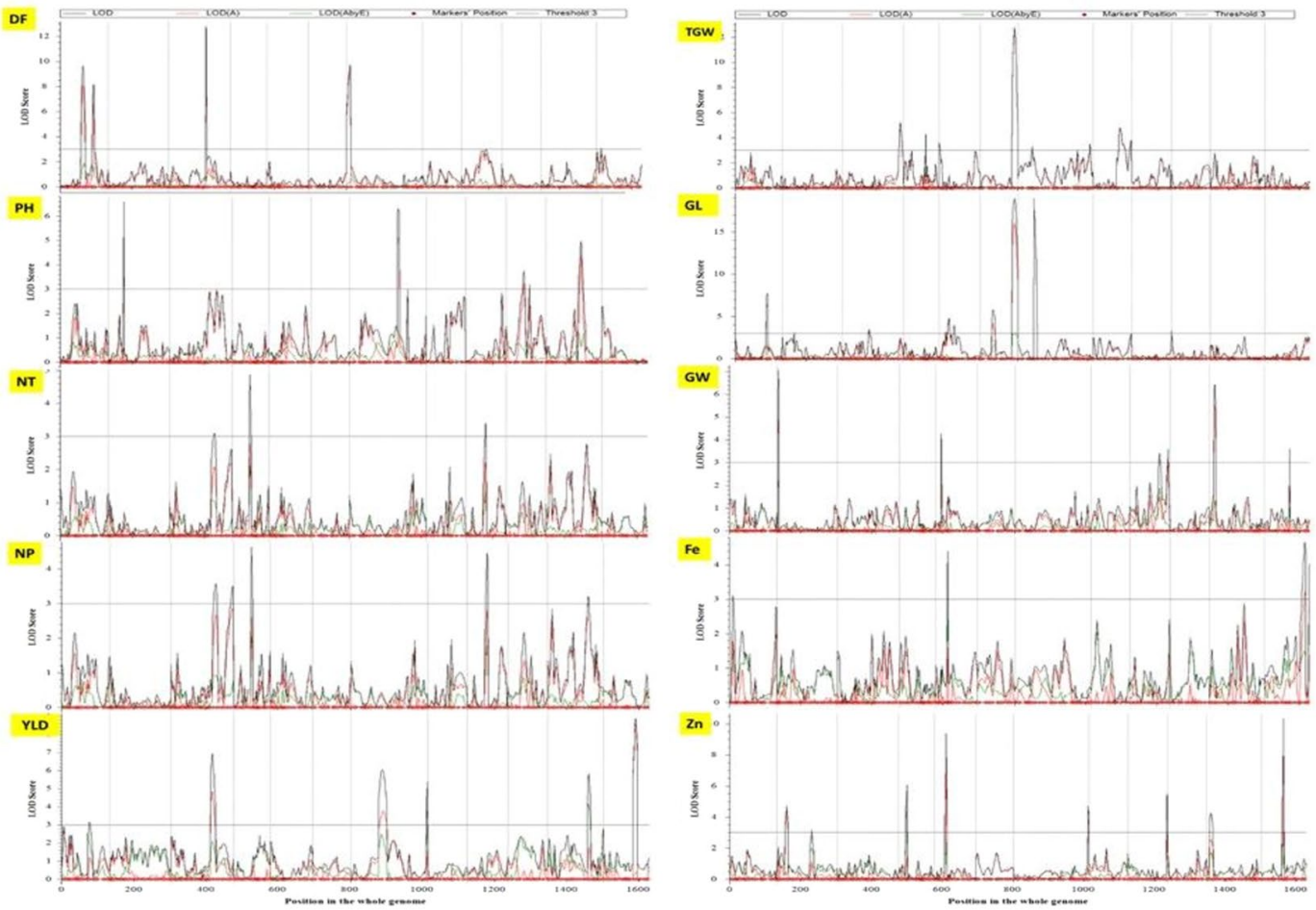

Figure 4. QTL by Environment Mapping: Chromosome locations of QTLs identified in the DH population.

GL and GW were among the phenotypic traits contributing positive projections while NT, NP, Fe and Zn contributing negative projections in two principal components which explained $30.34 \%$ and $25.60 \%$ of variation respectively. Through PCA we identified a number of traits which are responsible for the observed genotypic variation in the $\mathrm{DH}$ population, thereby identifying the traits with greatest impact on the phenotype of $\mathrm{DH}$ lines, which is informative for the selection of lines in breeding programs.

Analysis of relationships among quantitative traits is important for assessing the feasibility of joint selection of two or more traits and the effect of selection for secondary traits in genetic gain for the primary trait ${ }^{46}$. A positive genetic correlation between two desirable traits makes the job of the plant breeder easy in improving both traits simultaneously ${ }^{47}$. Clear insight on genetic correlations of agronomic traits and grain Fe and Zn concentrations can help plant breeder devise a suitable breeding strategy to enhance micronutrient density in rice. In the present study, DF was negatively correlated with TGW in BLUEs and across seasons, while PH was positively correlated with YLD. The trait NT was positively correlated with NP and YLD, but negatively correlated with GW. Similarly, GL was negatively correlated with Fe, while Fe and $\mathrm{Zn}$ were positively correlated. Previous studies also reported a positive correlation between grain $\mathrm{Fe}$ and $\mathrm{Zn}$ concentrations in rice ${ }^{15,16,39,40}$ which infers common mechanisms for uptake, translocation and loading of $\mathrm{Fe}$ and $\mathrm{Zn}$, and suggests that grain $\mathrm{Zn}$ can also be used for grain Fe selection. Negative correlations between YLD and $\mathrm{Zn}$ have also been observed ${ }^{39,40}$, though it was not consistent, and these 


\begin{tabular}{|l|l|l|l|l|l|}
\hline QTL & Gene names & Locus names & Location & GO/TO & Reference \\
\hline$q D F_{1.1}$ & OsLFL1 & Os01g0713600 & $2.49 \mathrm{Mb}$ left of QTL & flower development trait & (Peng et al., 2008) \\
\hline$q D F_{3.1}$ & OsHD6 & Os03g0762000 & $2.46 \mathrm{Mb}$ left of QTL & days to heading & (Takahashi et al., 2001) \\
\hline$q P H_{3.1}$ & OsLTS1 & Os03g0837300 & $1.20 \mathrm{Mb}$ right of QTL & plant height & \\
\hline$q Y L D_{3.1}$ & OsDST & Os03g0786400 & Within QTL & grain number & \\
\hline & OsIPT4 & Os03g0810100 & Within QTL & Grain number & (Liu et al., 2011) \\
\hline$q Y L D_{7.1}$ & OsMED5_3 & Os07g0681500 & $0.05 \mathrm{Mb}$ right of QTL & $\begin{array}{l}\text { 1000-seed weight/grain } \\
\text { width/grain yield }\end{array}$ & (Malik et al., 2016) \\
\hline$q Y L D_{12.1}$ & OsNAC139 & Os12g0477400 & $1.20 \mathrm{Mb}$ left of QTL & & \\
\hline$q G W_{5.1}$ & OsSRS3 & Os05g0154700 & $0.76 \mathrm{Mb}$ right of QTL & grain size & (Kitagawa et al., 2010) \\
\hline & OsGS5, OsSCP26 & Os05g0158500 & $1.00 \mathrm{Mb}$ right of QTL & grain shape & (Li et al., 2011) \\
\hline$q F e_{9.1}$ & OsLysM-RLK10, OsRLCK276 & Os09g0511000 & Within QTL & $\begin{array}{l}\text { 2Fe-2S cluster binding; } \\
\text { electron transporter }\end{array}$ & \\
\hline$q F e_{12.1}$ & SWEET13, OsSWEET13 & Os12g0476200 & Within QTL & haem binding & \\
\hline$q Z n_{1.1}$ & OsGATA8, OsGATA14 & Os01g0343300 & Within QTL & zinc binding & \\
\hline & OsARL1e, ARL1e, Sar1b & Os01g0338000 & Within QTL & zinc binding & \\
\hline$q Z n_{5.1}$ & OsZIP6 & Os05g0164800 & $0.38 \mathrm{Mb}$ right of QTL & $\begin{array}{l}\text { rice ferrous ion } \\
\text { transporter }\end{array}$ & (Ishimaru et al., 2005) \\
\hline$q Z n_{9.1}$ & & Os09g0511500 & Within QTL & zinc binding & \\
\hline
\end{tabular}

Table 4. Candidate genes for agronomic traits and grain Fe and $\mathrm{Zn}$ concentrations identified in the DH population.

\begin{tabular}{|l|l|l|c|}
\hline SN & QTL class & $\begin{array}{l}\text { Mean } \\
(\mathbf{p p m})\end{array}$ & $\begin{array}{c}\mathbf{E f f e c t}^{\mathrm{a}} \\
(\mathbf{p p m})\end{array}$ \\
\hline 1 & None & $11.18^{\mathrm{b}}$ & 0.00 \\
\hline 2 & $q Z n_{1.1}$ & $11.10^{\mathrm{b}}$ & -0.08 \\
\hline 3 & $q Z n_{5.1}$ & $12.43^{\mathrm{a}, \mathrm{b}}$ & 1.25 \\
\hline 4 & $q Z n_{9.1}$ & $11.84^{\mathrm{a}, \mathrm{b}}$ & 0.66 \\
\hline 5 & $q Z n_{12.1}$ & $13.05^{\mathrm{a}, \mathrm{b}}$ & 1.87 \\
\hline 6 & $q Z n_{1.1}+q Z n_{5.1}$ & $13.78^{\mathrm{a}, \mathrm{b}}$ & 2.60 \\
\hline 7 & $q Z n_{1.1}+q Z n_{12.1}$ & $13.47^{\mathrm{a}, \mathrm{b}}$ & 2.29 \\
\hline 8 & $q Z n_{5.1}+q Z n_{9.1}$ & $12.36^{\mathrm{a}, \mathrm{b}}$ & 1.18 \\
\hline 9 & $q Z n_{5.1}+q Z n_{12.1}$ & $14.74^{\mathrm{a}, \mathrm{b}}$ & 3.56 \\
\hline 10 & $q Z n_{1.1}+q Z n_{9.1}+q Z n_{12.1}$ & $15.25^{\mathrm{a}, \mathrm{b}}$ & 4.07 \\
\hline 11 & $q Z n_{5.1}+q Z n_{9.1}+q Z n_{12.1}$ & $15.73^{\mathrm{a}, \mathrm{b}}$ & 4.55 \\
\hline 12 & $q Z n_{1.1}+q Z n_{5.1}+q Z n_{9.1}+q Z n_{12.1}$ & $17.70^{\mathrm{a}}$ & 6.52 \\
\hline
\end{tabular}

Table 5. Means and effects of 12 QTL classes for Zn across three seasons. ${ }^{a}$ Difference to the class with no QTLs. ${ }^{b}$ Different letters indicate significant differences by Tukeys's Honest Significant Difference (HSD) Test multiple comparison of means by $\mathrm{P}<0.05$.

highlight the need for biofortification breeding programs to give significant weight to YLD while selecting for high grain $\mathrm{Zn}$ genotypes.

Considering the agronomic traits such as DF, PH, and YLD, Fe and Zn, the present study identified a DH line for which YLD was $6697.23 \mathrm{~kg} \mathrm{ha}^{-1}$ with a $\mathrm{Zn}$ content of $15.11 \mathrm{ppm}$ (IR 91153-AC 113-1). The high Zn lines identified in this study could be used in biofortification breeding programs to improve the grain $\mathrm{Zn}$ levels in rice resulting in improved rice varieties that could directly impact human nutrition, especially in populations that heavily rely on rice-based diets.

In this study, seventeen QTLs were mapped for agronomic traits and six QTLs were identified for Fe and Zn. It was notable that all the QTLs for grain Fe and Zn concentrations as well as QTLs for GW were derived from IR69428. Meanwhile, IR05F102 contributed all the QTLs for agronomic traits PH, NP, NT, YLD, TGW, and GL. These QTLs are good candidates for further studies such as gene fine-mapping and cloning. Our QTL results corroborated with recent studies on QTL mapping for agronomic traits and grain $\mathrm{Fe}$ and $\mathrm{Zn}$ concentrations in rice using diverse populations such as $\mathrm{RILs}^{26}, \mathrm{BILs}^{28}, \mathrm{BC}_{2} \mathrm{~F}_{3}$ derived lines ${ }^{19}$, DH lines ${ }^{15}$, and MAGIC lines ${ }^{40}$ that revealed multiple loci located on all rice chromosomes. Consequently, these QTLs were detected in different environments and genetic backgrounds. The above results clearly showed the complexity of agronomic traits and grain $\mathrm{Zn}$ concentration ${ }^{14,15,42}$. Since the present study used BLUE values which excluded environmental effects and magnify genetic effects, the QTLs identified in this study may well prove more useful in rice biofortification breeding programs than the QTLs identified using single environment phenotypic values.

Haplotypes for two stable and major effect QTLs for grain $\mathrm{Zn}$ were further examined (Fig. 5). For $q Z n_{5.1}$, two haplotypes, $\mathrm{CA}$ and $\mathrm{AG}$ were observed in the $\mathrm{DH}$ population indicating that there is a tight linkage between the 


\begin{tabular}{|c|c|c|c|c|c|c|}
\hline Designation & $\begin{array}{l}\text { DF } \\
\text { (days) }\end{array}$ & \begin{tabular}{|l} 
PH \\
$(\mathrm{cm})$
\end{tabular} & \begin{tabular}{|l} 
YLD \\
$\left(\mathrm{kg} \mathrm{ha}^{-1}\right)$
\end{tabular} & \begin{tabular}{|l} 
Fe \\
$($ ppm)
\end{tabular} & $\begin{array}{l}\mathrm{Zn} \\
(\mathrm{ppm})\end{array}$ & QTLs \\
\hline IR 91153-AC 113-1 & 88.25 & 98.13 & 6697.23 & 4.26 & 15.11 & $q Z n_{12.1}, q Y L D_{1.1}, q Y L D_{3,1}, q Y L D_{7.1}, q Y L D_{12.1}$ \\
\hline IR 91153-AC 325-1 & 88.61 & 91.09 & 5900.48 & 3.29 & 14.13 & $q Y L D_{1.1}, q Y L D_{3.1}, q Y L D_{7.1}, q Y L D_{12.1}$ \\
\hline IR 91153-AC 374-2 & $80.30^{*}$ & 94.71 & 5150.38 & 4.05 & 13.85 & $q Y L D_{1.1}, q Y L D_{7.1}$ \\
\hline IR 91153-AC 545-1 & 89.84 & 97.58 & 5648.43 & 4.09 & 14.47 & $q Z n_{9,1}, q Y L D_{3.1}, q Y L D_{12.1}$ \\
\hline IR 91153-AC 568-7 & $83.05^{*}$ & 92.03 & 6092.35 & 3.69 & 14.13 & $q Y L D_{1,1}, q Y L D_{3,1}$ \\
\hline IR 91153-AC 579-1 & 92.23 & 95.87 & 5942.92 & $4.71-$ & 13.84 & $q Y L D_{1.1}, q Y L D_{7.1}, q Y L D_{12.1}$ \\
\hline IR 91153-AC 701-1 & 93.92 & 98.89 & 5160.19 & 4.27 & 14.42 & $q Y L D_{1.1}, q Y L D_{7.1}, q Y L D_{12.1}$ \\
\hline IR 91153-AC 701-2 & 92.71 & 92.24 & 5689.03 & 4.28 & 13.88 & $q Y L D_{1.1}, q Y L D_{3.1}, q Y L D_{12.1}$ \\
\hline IR 91153-AC 722-1 & 93.72 & 88.69 & 5944.21 & 3.76 & 14.03 & $q Y L D_{1.1}, q Y L D_{3.1}, q Y L D_{12.1}$ \\
\hline IR 91153-AC 726-1 & 86.76 & 95.63 & 5006.42 & $4.82-$ & 16.21 & $q Z n_{5.1}, q Z n_{12.1}, q Y L D_{1.1}$ \\
\hline IR05F102 & 88.50 & 95.40 & 6425.10 & 3.60 & 3.90 & $q Y L D_{1.1}, q Y L D_{3.1}, q Y L D_{7.1}, q Y L D_{12.1}$ \\
\hline IR69428 & 94.50 & 98.90 & 3154.40 & 11.90 & 14.80 & $q Z n_{1.1}, q Z n_{5,1}, q Z n_{9,1,}, q Z n_{12.1}$ \\
\hline
\end{tabular}

Table 6. Agronomic traits and $\mathrm{Fe}$ and $\mathrm{Zn}$ concentrations of the parents and top ten high- $\mathrm{Zn}$ rice $\mathrm{DH}$ lines. ${ }^{\circledR} \mathrm{DF}$ : days to flowering (days); PH: plant height (cm); YLD: yield (kg ha-1); Fe: Iron (ppm); and Zn: Zinc (ppm).

two loci. The CA haplotype is associated with high $\mathrm{Zn}$. Similarly, the two haplotypes in $q Z n_{12,1}$ were GC and AA. The latter was associated with high $\mathrm{Zn}$. The stability of the markers in these loci has clearly shown its potential for use in biofortification breeding programs although further validation is still necessary.

Co-localized QTLs are important for simultaneous improvement of traits of interest such as grain Fe and $\mathrm{Zn}$ concentrations in rice from plant breeder point of view ${ }^{48}$. QTLs controlling correlated traits were usually mapped in the same or close chromosome regions ${ }^{49}$. Some previous studies have reported the phenomenon of QTL co-locations for rice micronutrient concentrations ${ }^{15,19,23}$. In this study, several co-located QTLs linked with correlated traits were identified on chromosomes 3 and 9. For instance in agronomic traits, $q D F_{3.1}$ and $q P H_{3.1}$ were co-localized on chromosome 3 in the same SNP marker interval 3500757-3501392. For grain Fe and Zn, $q F_{9.1}$ and $q Z n_{9.1}$ were co-localized in the same SNP marker interval 9809545-9819278. These co-located QTLs may be the result of pleiotropy or multiple tight linkage of genes controlling the traits ${ }^{50}$. These regions might be useful for development of high grain $\mathrm{Zn}$ rice with highly productive agronomic traits. The co-location of QTLs for Fe and $\mathrm{Zn}$ will be beneficial for their simultaneous improvement with Marker Assisted Breeding ${ }^{15,19,23}$.

Identification of environment-specific and stable QTLs having consistent genetic effects across a wide range of environments is of great importance in rice biofortification breeding ${ }^{37,40}$. Several QTLs for agronomic traits and grain $\mathrm{Fe}$ and $\mathrm{Zn}$ concentrations have been identified, but the positions, effect sizes and genetic effect directions of these QTLs were mostly genotype and environment specific ${ }^{51}$. Studies on QEI contribute to the effective use of marker-assisted selection (MAS) in biofortification breeding, better understanding of the genetic architecture of grain $\mathrm{Zn}$ and agronomic traits, and the interactions of the genotype and environment ${ }^{52}$. The QTLs that were only detected in one environment mostly showed poor stability. All the consistent QTLs identified in this study: one for DF; two for YLD, GL, and Zn; and three for GW based on QEI analysis confirms stability as indicated by higher $\mathrm{LOD}_{\mathrm{A}}$ and $\mathrm{PVE}_{\mathrm{A}}$ values as compared to $\mathrm{LOD}_{\mathrm{AE}}$ and $\mathrm{PVE}_{\mathrm{AE}}$ values. The environment plays only a minor role in the additive effects of these QTLs. For instance, the additive effects of Zn QTL $q Z n_{12.1}$ were 0.38 in S1, whereas in S2 the additive effects were only 0.11 .

Expression of the phenotype is a result of polygenes interacting to control complex traits ${ }^{53}$. Understanding epistatic interactions can be useful to target genes through marker-assisted selection strategies for the improvement of complex traits such as YLD and grain Zn. In this study, we detected one epistatic interaction on chromosomes 3 and 7 for $\mathrm{PH}$. The total variation explained by epistatic loci for $\mathrm{PH}$ were significant suggesting that epistasis in the form of additive by additive interactions, plays a very important role in controlling $\mathrm{PH}$.

Several QTLs harbor genes for agronomic traits and grain Fe and Zn concentration. In this study, genes for flowering development on the chromosome 1 and days to heading on chromosome 3 were co-located with QTLs identified for $\mathrm{DF}^{54,55}$. OsDST, OsIPT4, OsMED5_3, and OsNAC139 genes for grain number, 1000-seed weight, and grain width ${ }^{56}$ co-located with QTLs identified for YLD on chromosomes 3, 7, and 12. The candidate genes for grain $\mathrm{Fe}$ and $\mathrm{Zn}$ concentrations are involved in uptake, translocation, and metal homeostasis within rice plants. A network analysis of genes Sar1a and SWEET13 were conducted to understand their interaction with other traits and genes through the Knetminer program (Supplementary Figs. S3 and S4). Sar 1a was positioned within 12.71-13.79 Mb on chromosome 1 for Zn while SWEET13 was positioned within $16.98-17.57 \mathrm{Mb}$ on chromosome 12 for Fe. Six QTLs and 35 traits were linked to Sarla, while 12 QTLs and 42 traits were linked to SWEET13. A QTL for Zn on chromosome 5 was linked to candidate gene OsZIP6, which translocates Fe and Zn and may be responsible for high concentrations of these micronutrients in the grains ${ }^{57,58}$ These candidate genes which were tightly linked with QTLs identified are worthy of further investigation.

QTL pyramiding is successfully utilized in rice breeding to develop lines resistance/tolerance to biotic and abiotic stresses ${ }^{59,60}$. To evaluate the pyramiding effect of each QTL in the present study, we compared the means of YLD and Zn between genotype classes in all combinations. Although, the arithmetic mean of YLD of all the genotype classes were higher than that of class 1 (no QTLs), no significant differences were detected. However, the means of class $15\left(6373.00 \mathrm{~kg} \mathrm{ha}^{-1}\right)$ and class $16\left(6285.74 \mathrm{~kg} \mathrm{ha}^{-1}\right)$ were significantly higher than that of class $4\left(4129.43 \mathrm{~kg} \mathrm{ha}^{-1}\right)$. On the other hand, the mean $\mathrm{Zn}$ concentration of classes 3 to 11 ranged from 11.84 to 15.73 


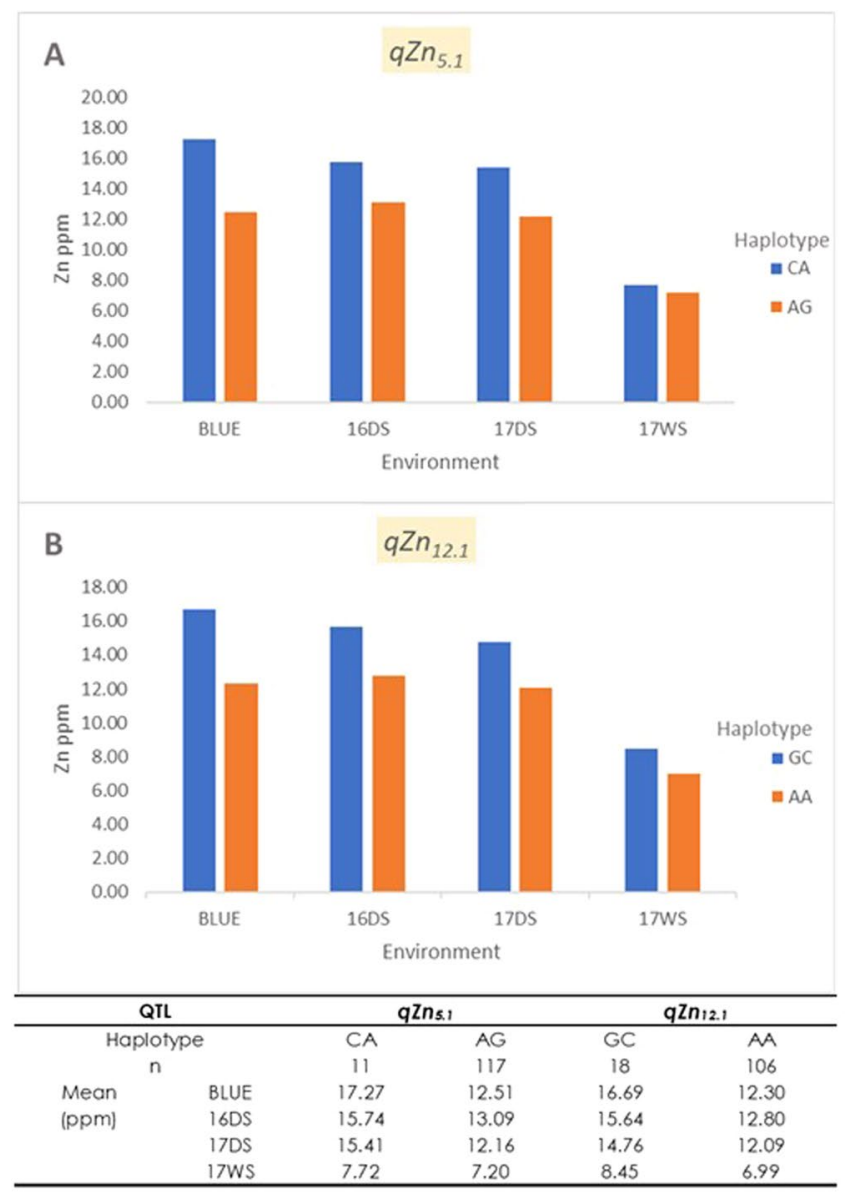

Figure 5. The haplotypes of the major effect QTLs for grain $\mathrm{Zn}, q Z n_{5.1}(\mathbf{A})$ and $q Z n_{12.1}(\mathbf{B})$, and their effect on Zn phenotype in different environments. Blue and orange color indicates different haplotypes within the QTLs, $\mathrm{n}$ indicates the number of $\mathrm{DH}$ lines with different haplotypes.

ppm, which was higher than that of class 0 , though there were no significant differences detected among these groups. A significant difference was detected between class $12(17.70 \mathrm{ppm})$ and class $1(11.18 \mathrm{ppm})$. Hence, it will be necessary to pyramid favorable alleles of Zn and YLD QTLs in popular variety background to accumulate a large number of desirable alleles.

\section{Conclusion}

The $\mathrm{DH}$ population showed wide variation for agronomic traits, grain Fe and $\mathrm{Zn}$. High heritability was obtained for DF, PH, and GL and moderate for TGW and Zn. Significant positive correlations between PH \& YLD, YLD \& GL, TGW \& GW, and Fe \& Zn were observed. Most of the QTL alleles associated with improved grain Zn and Fe were contributed by the donor parent IR69428. Six QTLs contributed more than 15\% of the phenotypic variance; $q N T_{3.1}, q N P_{3.1,} q Y L D_{3.1}, q T G W 6_{.1}, q G L_{6.1}$ and $q Z n 12_{.1 .}$ Based on QEI analysis, all the consistent QTLs were relatively stable. The epistatic QTL analysis detected one significant di-genic interaction for PH with $28.40 \%$ PVE. QTLs for grain $\mathrm{Fe}$ and $\mathrm{Zn}$ concentrations were associated with the candidate genes invovlved in metal homeostasis. A positive correlation between YLD and Zn levels was found in several combinations of three to four QTLs. The high $\mathrm{Zn}$ lines identified in this study could be used in biofortification breeding program to improve the grain $\mathrm{Zn}$ levels in rice resulting in improved rice varieties that could directly impact human nutrition.

\section{Methods}

Plant materials. A doubled-haploid (DH) population, derived from IR05F102 (P1) x IR69428 (P2) cross composed of 148 lines, was used in the study. The mapping population was evaluated under irrigated conditions during the dry seasons of 2016 and 2017 (S1, S2) and wet season of 2017 (S3) in Robert Zeigler Experimental Station (ZES) at International Rice Research Institute (IRRI), Los Baños (LB), Laguna. The experiment was laid out in Randomized Complete Block Design (RCBD) with two to three replications per trial. Seedlings were transplanted at 21 days with a spacing of $20 \times 20 \mathrm{~cm}$, and the plant population was 2 rows of 10 hills in each plot. Standard agronomic practices and plant protection measures were applied to ensure good crop growth and complete grain development. 
Phenotyping. The population was evaluated for eight agronomic traits and two grain mineral elements. The agronomic traits were measured following the standard evaluation system ${ }^{61}$, including days to $50 \%$ flowering (DF), plant height (PH), number of tillers (NT), number of panicles (NP), grain yield (YLD), thousand grain weight (TGW), grain length (GL), and grain width (GW). For grain Fe and $\mathrm{Zn}$ analysis, $50 \mathrm{~g}$ paddy samples were dehulled using a Satake dehuller and milled for one minute using a K-710 mini-lab rice polisher. Milled rice samples weighing at least $3 \mathrm{~g}$ representing each plot were analyzed using X-ray Fluorescence Spectrometry (XRF) $(\text { Oxford })^{62}$. Measurements were done twice per sample and was expressed in parts per million (ppm). The average reading per plot was considered for further statistical analysis.

Statistical analysis. A summary of basic statistical parameters was generated using STAR v.2.0.1. Analysis of Variance (ANOVA) was performed on single-season data and combined season data using one-stage multi-environment analysis implemented in PBTools v1.4. Best linear unbiased estimates (BLUEs) were generated by setting genotype effects as fixed and season effects as random. The BLUEs were used to perform QTL analysis. Boxplots and Pearson's correlation coefficients between pairs of traits were estimated using R Core team ${ }^{63}$.

The model used for ANOVA was:

$$
Y_{i j k o}=\mu+\alpha_{i}+r_{j}+l_{k j}+b_{o j k}+\varepsilon_{i j k o}
$$

where $\mu$ is the overall mean, $\alpha_{i}$ is the effect of the $i^{\text {th }}$ genotype; $r_{j}$ is the effect of the $j^{t h}$ season, $l_{k j}$ the effect of the $k^{\text {th }}$ replicate within the $j^{\text {th }}$ season, $b_{o j k}$ was the effect of the $o^{\text {th }}$ block at the $j^{\text {th }}$ season of the $k^{\text {th }}$ replicate and $\varepsilon_{i j k}$ the error. The genotypes were considered fixed while replicates and blocks within replicates were random.

Broad-sense heritability $\left(\mathrm{H}^{2}\right)$ for each trait in each season was calculated as:

$$
H^{2}=\frac{\sigma_{g}^{2}}{\sigma_{p}^{2}} \text { and } \sigma_{p}^{2}=\sigma_{g}^{2}+\frac{\sigma_{e}^{2}}{r}
$$

where $\sigma_{p}^{2}$ is the phenotypic variance, $\sigma_{g}^{2}$ is the genotypic variance, $\sigma_{e}^{2}$ is the error variance, and $\mathrm{r}$ is the number of replications.

Genotyping. Plant genomic DNAs were extracted from leaf tissue using the cetyl trimethylammonium bromide (CTAB) method $^{64}$. Quality check of DNA samples was carried out in $1 \%$ agarose gel. We submitted $\sim 50 \mathrm{ng}$ of DNA from the complete set of the doubled-haploid mapping population, along with the parents for genotyping with 7 K SNP array technology at the Genotyping Services Laboratory (GSL) at IRRI. Scanned image calls and automatic allele calling were loaded in the Illumina Genome Studio data analysis version V2011.1.

Linkage mapping and QTL analysis. The linkage map of the $\mathrm{DH}$ population was constructed using 379 high quality SNP markers using IciMapping v4.1 ${ }^{65}$. The distribution of SNP markers varied across chromosomes. The number of SNPs per chromosome ranged from 15 SNPs (chromosomes 8 and 9) to 57 SNPs (chromosome 3). The total length of the linkage map was $1,629.6 \mathrm{cM}$ while the average interval length was $4.3 \mathrm{cM}$ (Supplementary Fig. S5). The linkage map was created using Kosambi function ${ }^{66}$. For analysis of QTLs, the BLUEs of each line in the DH population were used. The permutation method was used to obtain an empirical threshold for claiming QTLs based on 1000 runs of randomly shuffling the trait values at $95 \%$ confidence level using the BIP function, whereas epistatic interactions were identified by setting the logarithm of odds (LOD) threshold value at 6.0 utilizing inclusive composite interval mapping (ICIM) model in QTL IciMapping ver.4.1. The MET function in ICIMapping was used to study QTL x Environment Interaction. QTLs were visualized using MapChart v.2.367.

Candidate gene analysis. The physical position of each QTL was determined by the position of the flanking SNP markers and genes physically located within or near QTLs for agronomic and grain Fe and Zn traits were considered candidate genes. Annotated genes with functions related to agronomic traits, metal transport and homeostasis were compiled and the physical positions of annotated genes were determined using the RAP DB Genome Browser ${ }^{68}$ (http://rapdb.dna.affrc.go.jp/viewer/gbrowse/ irgsp1). Annotation and functions attributed to different candidate genes were downloaded from Oryzabase ${ }^{69}$ (https://shigen.nig.ac.jp/rice/oryzabase/gene). A network of the top hit candidate genes and QTLs was created using K-netminer program ${ }^{70}$ (http://knetminer. rothamsted.ac.uk/Oryza_sativa/).

Received: 29 July 2019; Accepted: 24 January 2020;

Published online: 10 February 2020

\section{References}

1. Khush, G. S. What it will take to Feed 5.0 Billion Rice consumers in 2030. Plant. Mol. Biol. 59(1), 1-6, https://doi.org/10.1007/ s11103-005-2159-5 (2005).

2. Ricepedia, Rice as a crop. [Online] Available from, http://ricepedia.org/rice-as-a-crop/rice-productivity (2019).

3. Pradhan, P., Fischer, G., van Velthuizen, H., Reusser, D. E. \& Kropp, J. P. Closing Yield Gaps: How Sustainable Can We Be? PLoS One 10(6), e0129487, https://doi.org/10.1371/journal.pone.0129487 (2015).

4. Tripathy., S. K., Dash, M., Behera, S. K., Ithape, D. M. \& Maharana, M. Nutrient rich quality rice- a journey to healthy life. Adv. Plants Agric. Res. 7(5), 364-367 (2017).

5. Tripathi, D. K. et al. Micronutrients and their diverse role in agricultural crops: advances and future prospective. Acta Physiol. Plant. 37, 139, https://doi.org/10.1007/s11738-015-1870-3 (2015).

6. Welch R. M. \& Graham R. D. Breeding for micronutrients in staple food crops from a human nutrition perspective. J. Exp. Bot. 55(396):353 \pm 64 , https://doi.org/10.1093/jxb/erh064 PMID: 14739261 (2004). 
7. Hefferon, K. Biotechnological approaches for generating zinc-enriched crops to combat malnutrition. Nutrients. 11, 253, https://doi. org/10.3390/nu11020253 (2019).

8. Salgueiro, M. J. et al. The role of zinc in the growth and development of children. Nutr. 18(6), 510-519, https://doi.org/10.1016/ S0899-9007(01)00812-7 (2002).

9. Panopio, J. A. Crop Biofortification, key to achieving Millennium Development Goals (2010).

10. Bouis, H. E. \& Saltzman, A. Improving nutrition through biofortification: A review of evidence from HarvestPlus, 2003 through 2016. Glob. Food Security 12, 49-58, https://doi.org/10.1016/j.gfs.2017.01.009 (2017).

11. Sharma, A., Patni, B., Shankhdhar, D. \& Shankhdhar, S. C. Zinc-an indispensable micronutrient. Physiol. Mol. Biol. Plants 19, 11-20 (2013).

12. Graham, R., Senadhira, D., Beebec, S., Iglesiasc, C. \& Monasteriod, I. Breeding for trace mineral density in edible portions of staple food crops: Conventional approaches. Field Crop. Res. 60, 57-80 (1999).

13. Kumar, U. et al. Analysis and simulation of phenotypic plasticity for traits contributing to yield potential in twelve rice genotypes. Field Crop. Res. 202, 94-107 (2017).

14. Descalsota-Empleo, G. I. et al. Genetic dissection of grain nutritional traits and leaf blight resistance in rice. Genes 10, 30; https://doi. org/10.3390/genes10010030 (2019a).

15. Swamy, B. P. M. et al. Identification of genomic regions associated with agronomic and biofortification traits in DH populations of rice. PLoS One 13(8), e0201756, https://doi.org/10.1371/journal.pone.0201756 (2018b).

16. Inabangan-Asilo, M. A. et al. Stability and $\mathrm{G} x \mathrm{E}$ analysis of zinc-biofortified rice genotypes evaluated in diverse environments. Euphytica 215, 61 (2019).

17. Descalsota-Empleo, G. I. et al. Genetic mapping of QTL for agronomic traits and grain mineral elements in rice, Crop J, https://doi. org/10.1016/j.cj.2019.03.002 (2019b).

18. Zhang, M. et al. Mapping and validation of quantitative trait loci associated with concentrations of 16 elements in unmilled rice grain. Theor. Appl. Genet. 127(1), 137-165, https://doi.org/10.1007/s00122-013-2207-5 (2014)

19. Swamy, B. P. M. et al. QTL analysis for grain Iron and Zinc concentration in two O. nivara derived backcross populations. Rice Sci, Vol. 25, No. 3 (2018a).

20. Pfeiffer, W. et al. Biofortification in underutilized staple crops for nutrition in Asia and Africa. In Regional expert consultation on underutilized crops for food and nutritional security in Asia and the Pacific - Thematic, strategic papers and country status reports. Thematic Papers, Chapter 7, Pp.70-81. Bangkok, Thailand: Asia-Pacific Association for Agricultural Research Institutions (APAARI). November 13-15, (2017).

21. Murovec, J. \& Bohanec, B. Haploids and doubled haploids in plant breeding. In Abdurakhmonov, I. (ed.), Plant Breeding. InTech (2012).

22. Thomson, M. J. et al. Large-scale deployment of a rice $6 \mathrm{~K} \mathrm{SNP}$ array for genetics and breeding applications. Rice 10(1), 40, https:// doi.org/10.1186/s12284-017-0181-2 (2017).

23. Stangoulis, J. C. R., Huynh, B. L., Welch, R. M., Choi, E. Y. \& Graham, R. D. Quantitative trait loci for phytate in rice grain and their relationship with grain micronutrient content. Euphytica 154(3), 289-294, https://doi.org/10.1007/s10681-006-9211-7 (2007).

24. Du, J. et al. Environmental effects on mineral accumulation in rice grains and identification of ecological specific QTLs. Env. Geochem. Health 35(2), 161-170, https://doi.org/10.1007/s10653-012-9473-z (2013).

25. Huang, Y. et al. Variation in Mineral Elements in Grains of 20 Brown Rice Accessions in Two Environments, Food Chemistry, https:// doi.org/10.1016/j.foodchem (2015).

26. Ishikawa, R. et al. Detection of quantitative trait loci controlling grain zinc concentration using Australian wild rice, Oryza meridionalis, a potential genetic resource for biofortification of rice. PLoS One 12(10), e0187224, https://doi.org/10.1371/journal. pone.0187224 (2017).

27. Kaladhar, K. et al. Mapping quantitative trait loci for yield traits in $\mathrm{BC}_{2} \mathrm{~F}_{2}$ population derived from Swarna $\times$ O. nivara cross Rice Genet Newsl, 24, p. 10. (2008)

28. Hu, B.-L. et al. Mapping QTLs for mineral element contents in brown and milled rice using an Oryza sativa $\times$ O. rufipogon backcross inbred line population. Cereal Res. Commun. 44(1), 57-68, https://doi.org/10.1556/0806.43.2015.044 (2015).

29. Collard, B. C. \& Mackill, D. J. Marker-assisted selection: an approach for precision plant breeding in the twenty-first century. Philos. Trans. R. Soc. Lond. B Biol. Sci. 363, 557-572, https://doi.org/10.1098/rstb.2007.217030 (2008).

30. Chattopadhyay, K. et al. Detection of stable QTLs for grain protein content in rice (Oryza sativa L.) employing high throughput phenotyping and genotyping platforms. Sci. Rep. 9, 3196, https://doi.org/10.1038/s41598-019-39863-2 (2019).

31. Ogawa, D. et al. Haplotype-based allele mining in the Japan-MAGIC rice population. Sci. Rep. 8, 4379, https://doi.org/10.1038/ s41598-018-22657-3 (2018)

32. Malav, A. K. I. \& Chandrawat, K. S. Gene Pyramiding: An Overview. Int. J. Curr. Res. Biosci. Plant. Biol. 3(7), 22-28, https://doi. org/10.20546/ijcrbp.2016.307.004 (2016).

33. Cakmak, I. \& Kutman, U. B. Agronomic biofortification of cereals with zinc: a review. Eur. J. Soil. Sci. 69, 172-180, https://doi. org/10.1111/ejss.12437 (2018)

34. Miller, B. D. D. \& Welch, R. M. Food system strategies for preventing micronutrient malnutrition. Food Pol. 42, 115-128, https://doi. org/10.1016/j.foodpol.2013.06.008 (2013)

35. Neeraja, C. N. et al. Transporter genes identified in landraces associated with high zinc in polished rice through panicle transcriptome for biofortification. PLoS One 13(2), e0192362, https://doi.org/10.1371/journal.pone.0192362 (2018).

36. Swamy, B. P. M. et al. Advances in breeding for high grain Zinc in Rice. Rice 9(1), 49, https://doi.org/10.1186/s12284-016-0122-5 (2016).

37. Phuke, R. M. et al. Genetic variability, genotype $\times$ environment interaction, correlation, and GGE biplot analysis for grain iron and zinc concentration and other agronomic traits in RIL population of sorghum (Sorghum bicolor L. Moench). Front. Plant. Sci. 8, 712, https://doi.org/10.3389/fpls.2017.00712 (2017)

38. Gregorio, G. B., Senadhira, D., Htut, H. \& Graham, R. D. Breeding for trace mineral density in rice. Food Nutr. Bull. 21(4), 382-386, https://doi.org/10.1177/156482650002100407 (2000).

39. Gande, N. K. et al. Identification of putative candidate gene markers for grain zinc content using recombinant inbred lines (RIL) population of IRRI38 X Jeerigesanna. Afr. J. Biotechnol. 13(5), 657-663 (2014).

40. Descalsota, G. I. L. et al. Genome-wide association mapping in a rice MAGIC plus population detects QTLs and genes useful for biofortification. Front. Plant. Sci. 9, 1347, https://doi.org/10.3389/fpls.2018.01347 (2018).

41. Bai, X. F. et al. Quantitative trait loci for rice yield-related traits using recombinant inbred lines derived from two diverse cultivars. J. Genet. 90(2), 209-215, https://doi.org/10.1007/s12041-011-0057-y (2011).

42. Gande, N. K. et al. Evaluation of recombinant inbred lines of rice (Oryza sativa L.) for grain zinc content, yield related traits and identification of transegressant lines grown under aerobic conditions. Asian J. Exp. Biol. Sci. 4(4), 567-574 (2013).

43. Gangashetty, P. I., Salimath, P. M. \& Hanamaratti, N. G. Association analysis in genetically diverse non-basmati local aromatic genotypes of rice (Oryza sativa L.). Mol. Plant. Breed. 4, 4-8 (2013).

44. Shi, Z. et al. Molecular mapping of quantitative trait loci for three kernel-related traits in maize using a double haploid population. Mol. Breed. 37, 108 (2017).

45. Raji, A. A. Assessment of genetic diversity and heterotic relationships in African improved and local cassava (Manihet esculenta Crantz) germplasm. PhD thesis. University of Ibadan, Nigeria (2002). 
46. Dhurai, S. Y., Reddy, D. M. \& Ravi, S. Correlation and path analysis for yield and quality characters in rice (Oryza sativa L.). Rice Genomics Genet. 7(4), 1-6, https://doi.org/10.5376/rgg.2016.07.0004 (2016).

47. Mallimar, M. et al. Correlation studies for micronutrients, yield and yield components in $\mathrm{F}_{3}$ population of rice (Oryza Sativa $\mathrm{L}$.). Res. Environ. Life Sci. 9(9), 1140-1142 (2016).

48. Sahu, V. K., Nair, S. K., Vishwakarma, A. K., Verulkar, S. B. \& Chandel, G. QTL hotspots detected for yield contributing traits in rice (Oryza Sativa L.) using composite interval mapping analysis. Biosci Biotech Res Asia 14(1) (2017).

49. Li, F. et al. Genetic basis underlying correlations among growth duration and yield traits revealed by GWAS in rice (Oryza sativa L.). Front. Plant. Sci. 9, 650, https://doi.org/10.3389/fpls.2018.00650 (2018).

50. Chen, L. High-resolution QTL mapping for grain appearance traits and co-localization of chalkiness-associated differentially expressed candidate genes in rice. Rice 9, 48, https://doi.org/10.1186/s12284-016-0121-6 (2016).

51. Boer, M. P. et al. A mixed-model quantitative trait loci (QTL) analysis for multiple-environment trial data using environmental covariables for QTL-by-environment interactions, with an example in maize. Genet. 177, 1801-1813 (2007).

52. Monteverde, E. et al. Integrating molecular markers and environmental covariates to interpret genotype by environment interaction in rice (Oryza sativa L.) grown in subtropical areas. G3-GENES GENOME GENET, https://doi.org/10.1534/g3.119.400064 (2019).

53. Yang, Z. et al. Analysis of epistasis among QTLs on heading date based on Single Segment Substitution Lines in rice. Sci. Rep. 8, 3059, https://doi.org/10.1038/s41598-018-20690-w (2018).

54. Peng, L.-T. et al. Overexpression of transcription factor OsLFL1 delays flowering time in Oryza sativa. J. Plant. Physiol. 165(8), 876-885, https://doi.org/10.1016/j.jplph.2007.07.010 (2008).

55. Takahashi, Y. et al. Hd6, a rice quantitative trait locus involved in photoperiod sensitivity, encodes the $\alpha$ subunit of protein kinase CK2. PNAS 98(14), 7922-7927, https://doi.org/10.1073/pnas.111136798 (2001).

56. Malik, N. et al. An integrated genomic strategy delineates candidate mediator genes regulating grain size and weight in rice. Sci. Rep. 6, 23253, https://doi.org/10.1038/srep23253 (2016).

57. Banerjee, S. \& Chandel, G. Understanding the role of metal homeostasis related candidate genes in Fe/Zn uptake, transport and redistribution in rice using semi-quantitative RT-PCR. J. Plant. Mol. Biol. Biotechnol. 2(1), 33-46 (2011).

58. Nozoye, T. et al. Phytosiderophore efflux transporters are crucial for Iron acquisition in graminaceous plants. J. Biol. Chem. 286(7), 5446-5454, https://doi.org/10.1074/jbc.M110.180026 (2011)

59. Shamsudin, N. A. A. et al. Marker assisted pyramiding of drought yield QTLs into a popular Malaysian rice cultivar, MR219. BMC Genet. 17, 30, https://doi.org/10.1186/s12863-016-0334-0 (2016).

60. Das, G. et al. Improved Tapaswini having four BB resistance genes pyramided with six genes/QTLs, resistance/tolerance to biotic and abiotic stresses in rice. Sci. Rep. 8, 2413, https://doi.org/10.1038/s41598-018-20495-x (2018).

61. Standard Evaluation. System (SES) for Rice. IRRI. 5 (2013).

62. Paltridge, N. G., Palmer, L. J., Milham, P. J., Guild, G. E. \& Stangoulis, J. C. R. Energy-dispersive X-ray fluorescence analysis of zinc and iron concentration in rice and pearl millet grain. Plant. Soil. 361(1 $1 \pm 2), 251 \pm 260$ (2012).

63. R Core Team. R: A Language and Environment for Statistical Computing. R Foundation for Statistical Computing, Vienna, Austria, https://www.R-project.org/ (2018).

64. Murray, M. G. \& Thompson, W. F. Rapid isolation of high molecular weight plant DNA. Nucleic Acids Res. 8(19), 4321-4326, https:// doi.org/10.1093/nar/8.19.4321 (1980).

65. Meng, L., Li, H., Zhang, L. \& Wang, J. QTL IciMapping: Integrated software for genetic linkage map construction and quantitative trait locus mapping in biparental populations. Crop. J. 3(3), 269 \pm 83 (2015).

66. Kosambi, D. D. The estimation of the map distance from recombination values. Ann. Eugen. 12, 172-175 (1944).

67. Voorrips, R. E. MapChart: software for the graphical presentation of linkage maps and QTLs. J. Hered. 93(1), 77-8 (2002).

68. Sakai, H. et al. Rice Annotation Project Database (RAP-DB): An integrative and interactive database for rice genomics. Plant. Cell Physiol. 54(2), e6 (2013).

69. Yamazaki, Y., Sakaniwa, S., Tsuchiya, R., Nonomura, K. \& Kurata, N. Oryzabase: an integrated information resource for rice science. Breed. Science. 60, 544-548 (2010).

70. Hassani-Pak, K. et al. Developing integrated crop knowledge networks to advance candidate gene discovery. Appl. Transl. Genom. 11, 18-26 (2016).

\section{Acknowledgements}

Authors would like to thank HarvestPlus for funding the rice Zinc Biofortification Research. We thank the Head of Plant Breeding Division of IRRI for all the help, support and encouragement during the study. G.D.-E. wishes to thank DOST-ASTHRDP-NSC, and MC and ZMS thank ADB-JSP-IRRI for their scholarship grant and thesis support. Drs. Deepinder Grewal and Jessica Rey for the initial development of the DH population.

\section{Author contributions}

M.C. analyzed the data and prepared the draft manuscript, G.D.-E. assisted in draft preparation, A.F., M.I.-A., A.A., Z.S. and C.N. were involved in conducting the field experiments and gathering the data. J.H., T.B., A.L., M.M., M.D. and C.D. advised G.D.-E. and A.F. in the conduct of the study, reviewed the manuscript and provided critical comments. B.S. and R.R. conceptualized the study, designed the experiments, and edited the manuscript. All the authors have read and approved the manuscript.

\section{Competing interests}

The authors declare no competing interests.

\section{Additional information}

Supplementary information is available for this paper at https://doi.org/10.1038/s41598-020-59184-z.

Correspondence and requests for materials should be addressed to B.P.M.S.

Reprints and permissions information is available at www.nature.com/reprints.

Publisher's note Springer Nature remains neutral with regard to jurisdictional claims in published maps and institutional affiliations. 
(c) (i) Open Access This article is licensed under a Creative Commons Attribution 4.0 International License, which permits use, sharing, adaptation, distribution and reproduction in any medium or format, as long as you give appropriate credit to the original author(s) and the source, provide a link to the Creative Commons license, and indicate if changes were made. The images or other third party material in this article are included in the article's Creative Commons license, unless indicated otherwise in a credit line to the material. If material is not included in the article's Creative Commons license and your intended use is not permitted by statutory regulation or exceeds the permitted use, you will need to obtain permission directly from the copyright holder. To view a copy of this license, visit http://creativecommons.org/licenses/by/4.0/.

(C) The Author(s) 2020 